See Article page e243.

\section{Commentary: A picture is worth a thousand words: Improving surgical approaches using advanced multimodal cardiac imaging}

\author{
Ali Fatehi Hassanabad, MD, MSc, \\ Vishnu Vasanthan, MD, and \\ Paul W. M. Fedak, MD, PhD, FRCSC, FAHA
}

At the turn of the century, the editors of the New England Journal of Medicine identified diagnostic imaging as one of the top 10 medical advances in the last 1000 years. ${ }^{1}$ Indeed, advances in advanced multimodal imaging over the past 5 decades have significantly contributed to continued improvements in clinical outcomes for patients with cardiovascular diseases. From the simple chest radiograph to 4-dimensional flow aortic imaging, we can see health and disease with a depth and clarity like never before. $^{2}$ A better understanding of intracardiac structures and cardiac function was first established by the introduction of echocardiography in $1954 .{ }^{3,4}$ This was followed by the arrival of nuclear medicine, ${ }^{5-7}$ cardiac magnetic resonance imaging (CMR), ${ }^{8-10}$ and coronary computed tomography $(\mathrm{CT}){ }^{11,12}$ In addition to providing more information, each of these modalities has enhanced the precision and detail that can be accessed by cardiologists and cardiac surgeons. In fact, in some cases, clinical biomarkers based on images can be identified to predict outcomes. ${ }^{13}$ More recently, with the advent of 3-dimensional (3D) printing, clinicians can actualize such images and can best describe and teach cardiac malformations to patients, their families,

\footnotetext{
From the Section of Cardiac Surgery, Department of Cardiac Sciences, Libin Cardiovascular Institute, Cumming School of Medicine, Calgary, Alberta, Canada. Disclosures: The authors reported no conflicts of interest.

The Journal policy requires editors and reviewers to disclose conflicts of interest and to decline handling or reviewing manuscripts for which they may have a conflict of interest. The editors and reviewers of this article have no conflicts of interest.

Received for publication Jan 28, 2021; revisions received Jan 28, 2021; accepted for publication Jan 28, 2021; available ahead of print Feb 4, 2021.

Address for reprints: Paul W. M. Fedak, MD, PhD, FRCSC, FAHA, Foothills Medical Centre, C849, 1403 29th St NW, Calgary, Alberta, Canada T2N 2T9 (E-mail: pwfedak@ucalgary.ca).

J Thorac Cardiovasc Surg 2022;163:e247-8

$0022-5223 / \$ 36.00$

Copyright (c) 2021 by The American Association for Thoracic Surgery

http://dx.doi.org/10.1016/j.jtcvs.2021.01.125
}

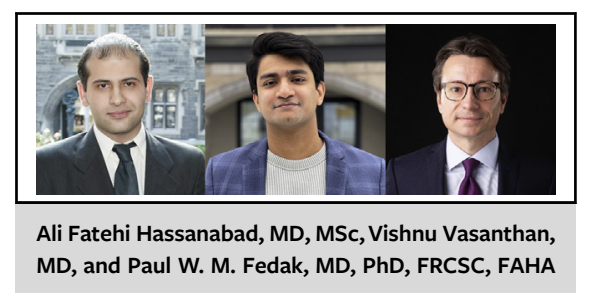

\section{CENTRAL MESSAGE \\ Technologic advances with \\ 3-dimensional image reconstruc- \\ tion can help visualize complex \\ patient-specific cardiac anatomy \\ and enhance both patient edu- \\ cation and surgical planning.}

and clinical trainees. ${ }^{14,15}$ Ideally, cardiovascular clinicians will integrate and combine various diagnostic imaging modalities to highlight normal versus abnormal anatomic variants, plan reparative operations, and anticipate the effect of interventions.

In this edition of the Journal, Oberoi and colleagues ${ }^{16}$ use multiphasic cardiac computed tomography (CT) to introduce an interactive 3D model of the different phenotypes of hypertrophic cardiomyopathy (HCM). The images were obtained from patients before they underwent septal myectomy, with advanced image processing tools used to segment the ventricles and the myocardium in 2 dimensions and then reconstruct them in 3D from different perspectives. ${ }^{16}$ Before this work, visual representations of HCM variants were limited to single-slice CT images. Given the expanding and important role of patient education, the authors' work will be a great help in explaining the morphological differences of HCM variants to patients and more effectively conveying the surgical plan to patients, their families, and trainees. In this era of precision and personalized medicine, the ability to use and combine accurate and descriptive imaging modalities can help facilitate optimal clinical outcomes. Finally, the emergence of virtual reality can take such patient-specific image reconstructions to ever greater heights. Realizing the potential of these powerful tools may help us explore new surgical frontiers for the next 1000 years.

\section{References}

1. Looking back on the millennium in medicine. N Engl J Med. 2000;342:42-9.

2. Wheatley GH III. Rise of the machines: the evolution of cardiovascular imaging for aortic disease. Innovations (Phila). 2020;15:502-5. 
3. Edler I, Hertz CH. The use of ultrasonic reflectoscope for the continuous recording of the movements of heart walls. 1954. Clin Physiol Funct Imaging. 2004;24:118-36

4. Yoshida T, Mori M, Nimura Y, Hikita G, Taka Gishi S, Nakanishi K, et al. Analysis of heart motion with ultrasonic Doppler method and its clinical application. Am Heart J. 1961;61:61-75.

5. Zaret BL, Strauss HW, Martin ND, Wells HP Jr, Flamm MD Jr. Noninvasive regional myocardial perfusion with radioactive potassium. Study of patients at rest, with exercise and during angina pectoris. N Engl J Med. 1973; 288:809-12.

6. Lebowitz E, Greene MW, Fairchild R, Bradley-Moore PR, Atkins HL, Ansari AN, et al. Thallium-201 for medical use. I. J Nucl Med. 1975;16:151-5.

7. Pohost GM, Zir LM, Moore RH, McKusick KA, Guiney TE, Beller GA. Differentiation of transiently ischemic from infarcted myocardium by serial imaging after a single dose of thallium-201. Circulation. 1977:55:294-302.

8. Goldman MR, Brady TJ, Pykett IL, Burt CT, Buonanno FS, Kistler JP, et al. Quantification of experimental myocardial infarction using nuclear magnetic resonance imaging and paramagnetic ion contrast enhancement in excised canine hearts. Circulation. 1982;66:1012-6.

9. Buonanno FS, Pykett IL, Brady TJ, Pohost GM. Clinical applications of nuclear magnetic resonance (NMR). Dis Mon. 1983;29:1-81.
10. Ratner AV, Okada RD, Newell JB, Pohost GM. The relationship between proton nuclear magnetic resonance relaxation parameters and myocardial perfusion with acute coronary arterial occlusion and reperfusion. Circulation. 1985;71:823-8.

11. Abdulla J, Abildstrom SZ, Gotzsche O, Christensen E, Kober L, TorpPedersen C. 64-multislice detector computed tomography coronary angiography as potential alternative to conventional coronary angiography: a systematic review and meta-analysis. Eur Heart J. 2007;28:3042-50.

12. Gopalakrishnan P, Wilson GT, Tak T. Accuracy of multislice computed tomog raphy coronary angiography: a pooled estimate. Cardiol Rev. 2008;16:189-96.

13. Fatehi Hassanabad A, Garcia J, Verma S, White JA, Fedak PWM. Utilizing wall shear stress as a clinical biomarker for bicuspid valve-associated aortopathy Curr Opin Cardiol. 2019;34:124-31.

14. Farooqi KM, Mahmood F. Innovations in preoperative planning: insights into another dimension using 3D printing for cardiac disease. J Cardiothorac Vasc Anesth. 2018;32:1937-45

15. Hadeed K, Acar P, Dulac Y, Cuttone F, Alacoque X, Karsenty C. Cardiac 3D printing for better understanding of congenital heart disease. Arch Cardiovasc Dis. 2018;111:1-4.

16. Oberoi M, Foley TA, Schaff HV. Hypertrophic cardiomyopathy: interactive 3-dimensional modeling of phenotypic variants. J Thorac Cardiovasc Surg. 2022; 163:e243-5.

\section{Commentary: Prevention of incomplete resection during septal myectomy: Virtual seeing is actual believing}

\author{
Edward Buratto, MBBS, PhD, ${ }^{\mathrm{a}, \mathrm{b}, \mathrm{c}}$ and \\ Igor E. Konstantinov, MD, PhD, FRACS ${ }^{\mathrm{a}, \mathrm{b}, \mathrm{c}, \mathrm{d}}$
}

Extended myectomy is the gold standard for treating hypertrophic obstructive cardiomyopathy (HOCM), and it can be achieved with low complication rates in high-volume institutions. ${ }^{1-5}$ Of interest, recurrent obstruction is rare in such

\footnotetext{
From the ${ }^{\text {a}}$ Department of Cardiac Surgery, Royal Children's Hospital, Melbourne, Australia; ${ }^{\mathrm{b}}$ Department of Paediatrics, University of Melbourne, Melbourne, Australia; 'Heart Research Group, Murdoch Children's Research Institute, Melbourne, Australia; and ${ }^{\mathrm{d}}$ Melbourne Centre for Cardiovascular Genomics and Regenerative Medicine, Melbourne, Australia.

Disclosures: The authors reported no conflicts of interest.

The Journal policy requires editors and reviewers to disclose conflicts of interest and to decline handling or reviewing manuscripts for which they may have a conflict of interest. The editors and reviewers of this article have no conflicts of interest.

Received for publication Jan 14, 2021; revisions received Jan 14, 2021; accepted for publication Jan 14, 2021; available ahead of print Jan 20, 2021.

Address for reprints: Igor E. Konstantinov, MD, PhD, FRACS, Royal Children's Hospital, Flemington Rd, Parkville 3052, Australia (E-mail: igor.konstantinov@rch. org.au).

J Thorac Cardiovasc Surg 2022;163:e248-50

$0022-5223 / \$ 36.00$

Crown Copyright $\odot 2021$ Published by Elsevier Inc. on behalf of The American Association for Thoracic Surgery

http://dx.doi.org/10.1016/j.jtcvs.2021.01.052
}

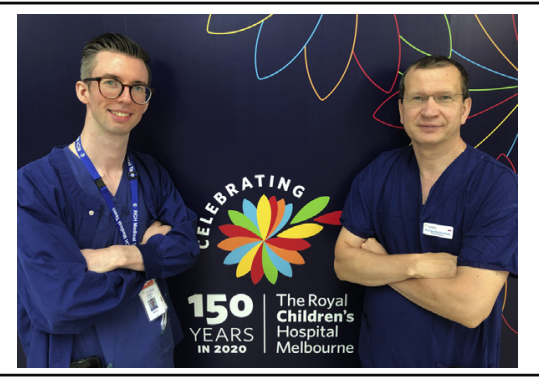

Edward Buratto, MBBS, PhD, and Igor E. Konstantinov, MD, PhD, FRACS, at the Royal Children's Hospital, Melbourne.

CENTRAL MESSAGE

The depth, length, and width of septal myectomy are all important to prevent residual

high-volume institutions. $^{1-5}$ obstruction.

It is becoming increasingly apparent that the vast majority of so-called "recurrences" are in fact consequences of incomplete initial resection. Conversely, excessive resection may result in conduction abnormalities and iatrogenic ventricular septal defects. ${ }^{2}$ The matter is further complicated by the variable morphology of HOCM and the relative scarcity of these patients at many institutions. Traditionally, septal morphology is assessed primarily with 2-dimensional (2D) echocardiography, with magnetic resonance imaging used in selected cases. $^{5}$ More recently, 3-dimensional (3D) computed 